\title{
Adição de lignina Kraft à resina fenólica para a fabricação de compensados
}

\author{
Mateus Alves de Magalhães ${ }^{1}$, Benedito Rocha Vital' ${ }^{1}$, Angélica de Cássia Oliveira Carneiro', \\ Carlos Miguel Simões da Silva ${ }^{1}$, Lucas de Freitas Fialho ${ }^{1 *}$, Clarissa Gusmão Figueiró, \\ Juliana Ceccato Ferreira ${ }^{2}$
}

${ }^{1}$ Departamento de Engenharia Florestal, Universidade Federal de Viçosa, Viçosa, MG, Brasil.

${ }^{2}$ Engenharia Florestal, Universidade Federal de Jataí, Jataí, GO, Brasil.

\begin{abstract}
RESUMO A maior parte das resinas utilizadas na produção de painéis reconstituídos é sintetizada a partir de compostos orgânicos advindos do petróleo que, além de não renováveis e relativamente caros, ainda apresentam riscos à saúde. O objetivo do trabalho foi produzir e caracterizar resinas de fenol-formaldeído com a adição de lignina Kraft de folhosas para a confecção de painéis compensados. A lignina foi obtida por meio da precipitação do licor negro proveniente do processo de polpação Kraft industrial de madeira de eucalipto. Os compensados foram fabricados com resina fenol-formaldeído (FF), resina fenolformaldeído com substituição parcial de lignina Kraft fenolada (L-FF), lignina tratada termicamente (LT-FF) e lignina tratada com dicromato de potássio (LD-FF). Estes adesivos foram comparados com a resina comercial FF, considerada como controle. A utilização de lignina Kraft como substituta parcial (50\%) do fenol em adesivos fenol-formaldeído foi considerada eficiente na fabricação de compensados. Dentre os tipos de ligninas testados, recomenda-se a utilização de L-FF, uma vez que produziram compensados com propriedades físicas e mecânicas semelhantes aqueles produzidos com LT-FF e LD-FF, consumindo uma menor quantidade de energia e/ou reagente.
\end{abstract}

Palavras-chave: Biorrefinaria; lignina modificada; fenol-formaldeído.

\section{Addition of Kraft lignin to phenolic resin for plywood production}

\begin{abstract}
Most of the resins used in the production of reconstituted panels are synthesized from organic compounds derived from petroleum which, in addition to being non-renewable and relatively expensive, still present health risks. The objective of the work was to produce and characterize phenol-formaldehyde resins with the addition of Kraft lignin of hardwoods for the manufacture of plywood. Lignin was obtained by precipitation of the black liquor from the industrial Kraft pulping process of eucalyptus wood. The plywood were manufactured with phenol formaldehyde resin (PF), phenol-formaldehyde partial substitution resin Kraft phenolated lignin (L-FF), thermally treated lignin (LT-FF) and lignin treated with potassium dichromate (LD-FF). These adhesives were compared with the commercial FF resin, considered as a control. The use of Kraft lignin as a partial substitute of phenol in phenol-formaldehyde adhesives (50\%) was considered efficient in the manufacture of plywood. Among the types of lignins tested, the use of L-FF is recommended. Plywood produced with such resin exhibit physical and mechanical properties similar to those produced with LT-FF and LD-FF, consuming a smaller amount of energy and / or reagent.
\end{abstract}

Keywords: Biorefinery; modified lignin; phenol formaldehyde 


\section{Introdução}

A demanda por matérias-primas renováveis e ambientalmente seguras, que possam substituir totalmente ou parcialmente o petróleo, aumenta o interesse por "biorrefinarias”. Na área florestal, esse termo está associado principalmente às fábricas de polpação Kraft, que além da celulose e seus derivados, produz lignina como coproduto da polpação (HU et al., 2018), que é utilizado principalmente como combustível nas caldeiras da própria indústria (GELLERSTEDT, 2015). Contudo, pesquisas evidenciam o potencial de utilização da lignina como insumo na produção de materiais de maior valor agregado.

Um dos possíveis usos da lignina Kraft é a fabricação de resinas para a colagem de madeira e confecção de painéis reconstituídos (IBRAHIM et al., 2013). Os painéis reconstituídos são estruturas fabricadas com madeira em lâminas ou em partículas, que são aglutinadas, visando à substituição da madeira maciça em diversos setores da manufatura. Dentre os tipos de painéis reconstituídos, os painéis compensados são aqueles produzidos pela junção de lâminas em número ímpar e direção da grã perpendicular entre as camadas adjacentes.

Atualmente, a maior parte das resinas utilizadas para esses fins é sintetizada a partir de compostos orgânicos advindos do petróleo que, além de não serem renováveis e relativamente caros, ainda apresentam riscos à saúde por normalmente apresentarem índices consideráveis de toxidade. O principal composto utilizado é o fenol, que apresenta estrutura similar à da lignina, o que a torna uma promissora substituta do fenol na síntese de resinas (PANG et al., 2017).

Portanto é necessário separar a lignina do licor negro, que é normalmente feito pela sua precipitação modificando-se o pH da solução. Após essa etapa, a maior dificuldade para a síntese da resina está na baixa reatividade da lignina Kraft. Apesar das similaridades com o fenol, a lignina apresenta grupos de metil ligados ao anel aromático dificultando ou até impossibilitando a ligação química com outros compostos, mesmo após as modificações ocorridas na sua estrutura durante a polpação (ASMADI et al., 2017). Em função dessa baixa reatividade, atualmente não é possível a substituição completa do fenol por lignina, uma vez que a qualidade da resina seria bastante inferior à exigida pelo mercado (PANG et al., 2017).

A reatividade é ainda menor para lignina oriunda de madeira de folhosas, em função da presença da lignina do tipo siringil, que a apresenta um grupo metil a mais que a do tipo guaiacil, única lignina presente nas coníferas (ZHAO et al., 2014). Essa dificuldade é evidenciada nos poucos estudos envolvendo a síntese de resinas com adição de lignina Kraft de folhosas com relação à quantidade expressiva de estudos utilizando lignina de coníferas (KALAMI et al., 2018). Contudo, existem alguns trabalhos que envolvem prétratamentos térmicos e químicos da lignina de coníferas, que poderiam ser testados para aumentar a reatividade também das ligninas de folhosas (FIGUEIREDO et al., 2017; WANG et al., 2019; ZHAO et al., 2016). Nesse contexto, o objetivo do presente estudo foi produzir e caracterizar resinas de fenolformaldeído com a adição de lignina Kraft de folhosas para a confecção de painéis compensados.

\section{Material e Métodos}

\section{Obtenção e Tratamento da Lignina}

A lignina utilizada neste estudo foi doada por uma empresa de papel e celulose, sendo obtida pela precipitação do licor negro oriundo do processo de polpação Kraft da madeira de eucalipto. A precipitação foi realizada por meio da modificação do $\mathrm{pH}$ do licor, obtendo-se um material em 
pó, que foi utilizado no estudo. Algumas propriedades da lignina Kraft utilizada estão apresentadas na Tabela 1.

Tabela 1. Propriedades da lignina Kraft

Table 1. Properties of Kraft lignin

\begin{tabular}{lc}
\hline Propriedades & Média \\
\hline UEH (\%) & 5,0 \\
pH & 3,4 \\
Lignina total (\%) & 98,06 \\
Teor de cinzas & 1,5
\end{tabular}

Legenda: UEH = Umidade de equilíbrio higroscópico.

Para redução e homogeneização da granulometria, a lignina foi primeiramente passada em um moinho do tipo pulverizador Fritsch, com rotação média de 16.000 rpm, antes da produção das resinas.

\section{Tratamento térmico}

De acordo com testes preliminares, o tratamento térmico aplicado na lignina foi o aquecimento a $300^{\circ} \mathrm{C}$ por 6 minutos. O material foi acondicionado dentro do container metálico que foi inserido dentro de um forno elétrico do tipo mufla (Figura 1). O container foi conectado ao meio externo mediante um tubo metálico que permitia sua movimentação constante e a liberação dos compostos voláteis advindos da degradação parcial da lignina. Após o tratamento, o container foi resfriado em água. A lignina termicamente modificada foi então pilada com ajuda de um almofariz e um pistilo, para se desfazer os aglomerados formados.

\section{Tratamento com dicromato de potássio}

Foram adicionados $100 \mathrm{~g}$ de lignina Kraft pulverizada e $750 \mathrm{ml}$ de dicromato de potássio $\left(0,033 \mathrm{M} \mathrm{K}_{2} \mathrm{Cr}_{2} \mathrm{O}_{7}\right)$ em dois litros de água destilada. $\mathrm{O}$ béquer com a solução foi mantido sob agitação moderada em banho-maria na temperatura de $40{ }^{\circ} \mathrm{C}$. O pH da solução foi mantido em aproximadamente 4 com a adição controlada de ácido acético. Após duas horas de tratamento, a solução foi retirada do banho-maria e o seu pH foi mensurado novamente. A suspensão foi submetida a filtros de porcelana com sucção forçada e seca ao ambiente. $\mathrm{O}$ tratamento com dicromato de potássio seguiu a metodologia descrita por Olivares et al. (1988), para a desmetilação da lignina oriunda do licor negro da polpação.

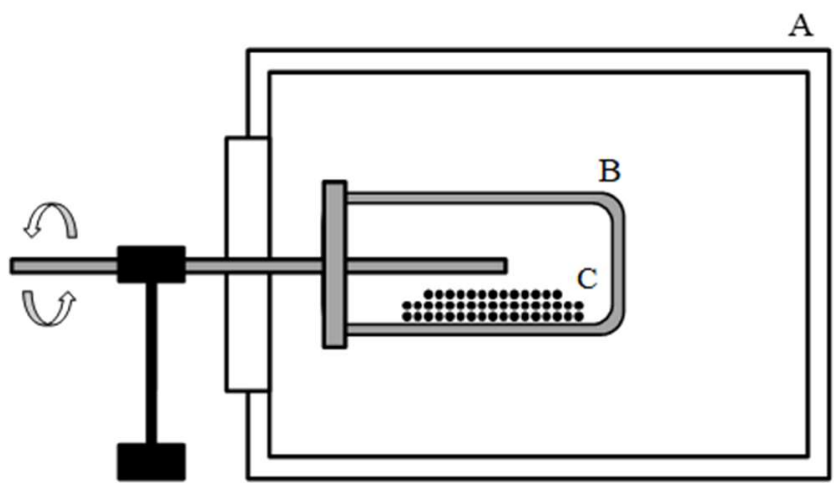

Figura 1. Layout do tratamento térmico da lignina. A: Forno elétrico do tipo mufla; B: Container metálico com movimentação e saída dos compostos voláteis; C: Lignina.

Figure 1. Layout of the heat treatment of lignin. Being: A: Muffle; B: Metal container with movement and exit of volatile compounds; C: Lignin.

\section{Síntese e Caracterização das Resinas}

Além da resina comercial de fenol-formaldeído (FF) utilizado como controle, foram produzidas mais três resinas de fenol-formaldeído com adição de lignina Kraft, sendo uma com a lignina na condição in natura pós-precipitação (L-FF), uma com lignina tratada termicamente (LT-FF) e outra com lignina tratada com dicromato de potássio (LD-FF), totalizando quatro resinas.

O procedimento adotado para a produção das resinas seguiu a metodologia utilizada por Khan et al. (2004). A síntese da resina foi dividida em duas etapas, sendo a primeira de fenolação e a segunda de adição do formaldeído. A etapa de fenolação foi aplicada para aumentar a reatividade das 
ligninas Kraft com o formaldeído, uma vez que, a lignina Kraft na condição in natura pós-precipitação apresenta baixa reação de polimerização da resina (YANG et., 2014). O procedimento consistiu na mistura de aproximadamente 137 $\mathrm{g}$ de lignina e $137 \mathrm{~g}$ de fenol (50\% em massa seca), em um balão de fundo chato de duas entradas. A mistura foi mantida por 60 minutos em banho-maria a uma temperatura de $40^{\circ} \mathrm{C}$ sob agitação moderada.

$\mathrm{Na}$ etapa seguinte, foram adicionados aproximadamente $460 \mathrm{~g}$ de formaldeído e $24 \mathrm{~g}$ de metanol a mistura. O balão foi então acoplado a um condensador de refluxo e aquecimento até $80{ }^{\circ} \mathrm{C}$ com agitação constante, permanecendo por 85 minutos depois de atingida a temperatura desejada. A agitação foi realizada por um agitador magnético e o controle de temperatura foi realizado com um termômetro inserido na outra entrada do balão. Foram adicionadas três cargas de $27 \mathrm{~g}$ de hidróxido de sódio $(\mathrm{NaOH})$, sendo a primeira no início, outra a 17 minutos após atingido a temperatura desejada e a última a 52 minutos.

Após 24 horas da síntese das resinas, foi determinada a viscosidade (cP) (ASTM, 1997) utilizando um viscosímetro de Brookfield (cP), com haste número 3 e velocidade de 12 rpm. O pH foi determinado com um pHmêtro digital. A quantificação do teor de sólidos foi realizada pela relação entre a massa final da amostra de resina, seca em estufa a $100 \pm 3^{\circ} \mathrm{C}$ por 24 horas, pela sua massa inicial. O tempo de gelatinização foi realizado em um tubo de ensaio imerso em glicerina à temperatura de $170{ }^{\circ} \mathrm{C}$, com constante movimentação de uma haste de vidro até que a resistência da resina atingisse a fase de gel.

\section{Confecção e Caracterização dos Painéis}

\section{Compensados}

Cada painel foi confeccionado com três lâminas de Pinus sp. com espessura de $1 \mathrm{~mm}$ cada uma delas, adquiridas junto a marcenaria da Universidade Federal de Viçosa. As lâminas foram esquadrejadas nas dimensões finais de $40 \mathrm{~cm}$ por $40 \mathrm{~cm}$ e secas em estufa a $60^{\circ} \mathrm{C}$ por 12 horas para uniformização da umidade. A gramatura para todos os adesivos foi igual a de $250 \mathrm{~g} / \mathrm{m}^{2}$. Os painéis foram primeiramente pré-prensados a $0,01 \mathrm{kgf} / \mathrm{cm}^{2}$ por seis minutos à temperatura ambiente. Posteriormente, foram prensados a $15 \mathrm{kgf} / \mathrm{cm}^{2}$ por oito minutos à temperatura de $170{ }^{\circ} \mathrm{C}$. Foram produzidos três painéis por tratamento.

De cada painel foram retirados dois corpos de prova para determinação da resistência à flexão paralela às fibras e dois para a flexão perpendicular; seis corpos de provas para o teste de cisalhamento a seco e seis a úmido, 8 corpos de provas para o teste de inchamento em espessura, ambos após imersão em água a $25^{\circ} \mathrm{C}$ por 24 horas e três corpos de prova para a determinação da massa específica. Os corpos de prova foram acondicionados em uma sala climatizada à temperatura de $\pm 23{ }^{\circ} \mathrm{C}$ e umidade relativa de $\pm 65 \%$, até o seu equilíbrio. Os testes de flexão, cisalhamento e as propriedades físicas dos painéis compensados foram realizados de acordo com a norma ABNT NBR 12466-1 (2006).

\section{Resultados e Discussão}

\section{Resinas}

O teor de sólidos da resina LD-FF foi significativamente maior, devido a utilização do dicromato de potássio em sua formulação (Tabela 2). Tal resultado pode ser justificado pela presença de sais que não reagiram na produção da resina. $\mathrm{O}$ teor de sólidos está relacionado à fração da resina que atuará formando a junta colada no produto final (IWAKIRI, 2005).

Foi observada a redução da viscosidade das resinas com lignina quando comparadas com a resina FF comercial. A viscosidade das resinas contendo a lignina modificada foi maior do que a viscosidade da resina de lignina não modifi- 
Tabela 2. Valores médios das propriedades das resinas

Table 2. Mean values of resin properties

\begin{tabular}{ccccc}
\hline Tratamento $^{\star}$ & Teor de Sólidos $(\%)$ & Viscosidade $(\mathrm{cP})$ & $\mathrm{pH}$ & Tempo de gelatinização (min) \\
\hline FF - Controle & $53,41 \mathrm{~b}$ & $237,50 \mathrm{a}$ & $9,75 \mathrm{a}$ & $1,66 \mathrm{a}$ \\
L-FF & $51,90 \mathrm{c}$ & $97,50 \mathrm{c}$ & $9,95 \mathrm{a}$ & $1,91 \mathrm{a}$ \\
LT-FF & $51,74 \mathrm{c}$ & $150,00 \mathrm{~b}$ & $9,85 \mathrm{a}$ & $1,57 \mathrm{a}$ \\
LD-FF & $55,33 \mathrm{a}$ & $135,00 \mathrm{~b}$ & $9,54 \mathrm{~b}$ & $2,05 \mathrm{a}$ \\
\hline
\end{tabular}

* FF = fenol-formaldeído; L-FF = lignina na condição in natura pós-precipitação; LT-FF = lignina tratada termicamente; LD$\mathrm{FF}=$ lignina tratada com dicromato de potássio. Médias seguidas por letras distintas diferem entre si $(\mathrm{p} \leq 0,05)$ pelo teste de Tukey.

cada, indicando que a modificação da lignina pode ter promovido um aumento de sua reatividade. Segundo Ferdosian et al. (2017) a viscosidade tem efeito direto na capacidade de penetração da resina na madeira. A menor viscosidade favorece a aplicação da resina pelos equipamentos utilizados na indústria, no entanto, a baixa viscosidade pode acarretar excessiva penetração da resina na madeira, formando uma linha de cola delgada e de baixa resistência (IWAKIRI et al., 2012).

Observou-se pequena variação no $\mathrm{pH}$ das resinas sendo o menor valor observado na formulação LD-FF. Os valores obtidos estão dentro da faixa aceitável para utilização na colagem de produtos de madeira (DAMÁSIO et al., 2017). Resinas excessivamente ácidas ou básicas podem causar a degradação da madeira, afetando a integridade da junta colada (IWAKIRI et al., 2002).

Não houve efeito do tratamento no tempo de gelatinizacão, indicando que o uso da lignina em substituição ao fenol na resina não afeta o tempo de cura do mesmo. A indústria tem preferência em resinas com menor tempo de cura, para redução do tempo de prensagem, com consequente aumento de produção (DAMÁSIO et al., 2017).

\section{Compensados}

Na Tabela 3 pode-se observar os valores médios de massa específica e inchamento em espessura dos compensados por tipo de resina. Verifica-se que tanto para massa específica, quanto para inchamento em espessura, não foram constatadas diferenças significativas entre as resinas. Os valores médios variaram de 463 a $506 \mathrm{Kg} / \mathrm{m}^{3}$ e 2,56 a $4,09 \%$ para massa específica e inchamento em espessura, respectivamente.

A massa específica depende da espécie da madeira, da umidade das lâminas, da temperatura e pressão de prensagens utilizadas na sua produção. Quando não são aplicadas pressões elevadas, a densidade do compensado é

Tabela 3. Valores médio da massa específica e flexão estática perpendicular dos painéis

Table 3. Mean values of the specific gravity and perpendicular static flexion of the plywood

\begin{tabular}{ccccc}
\hline \multirow{2}{*}{ Tratamento $^{*}$} & \multicolumn{2}{c}{ Massa específica } & \multicolumn{2}{c}{ Inchamento em espessura } \\
\cline { 2 - 5 } & Média $\left(\mathrm{kg} / \mathrm{m}^{3}\right)$ & Desvp. $\left(\mathrm{kg} / \mathrm{m}^{3}\right)$ & Média (\%) & Desvp. (\%) \\
\hline FF - Controle & 505,61 & 45,44 & 3,68 & 1,25 \\
L-FF & 484,84 & 79,85 & 3,75 & 0,77 \\
LT-FF & 462,97 & 42,42 & 2,56 & 0,80 \\
LD-FF & 489,35 & 88,59 & 4,09 & 1,40
\end{tabular}

* Desvp. = desvio padrão da média; FF = fenol-formaldeído; L-FF = lignina na condição in natura pós-precipitação; LT-FF = lignina tratada termicamente; $\mathrm{LD}-\mathrm{FF}=$ lignina tratada com dicromato de potássio. 
cerca de $5 \%$ maior que o da madeira que lhe deu origem (KOLLMANN et al., 1975).

O inchamento em espessura de um compensado é ocasionado pela absorção de água que libera as tensões de compressão originadas na prensa. Essas tensões aumentam na medida em que se aumenta o tempo e a pressão de prensagem (ALMEIDA et al., 2004). Possivelmente devido a semelhança química entre a molécula fenólica e a molécula de lignina (Kalami et al., 2017) não foram observadas diferenças significativas entre as resinas para o inchamento em espessura.

Os valores médios para a tensão de cisalhamento na linha de cola das resinas sintetizadas, tanto para fenol formaldeído quanto para os com substituição de $50 \%$ de lignina não diferiram entre si (Figura 2).

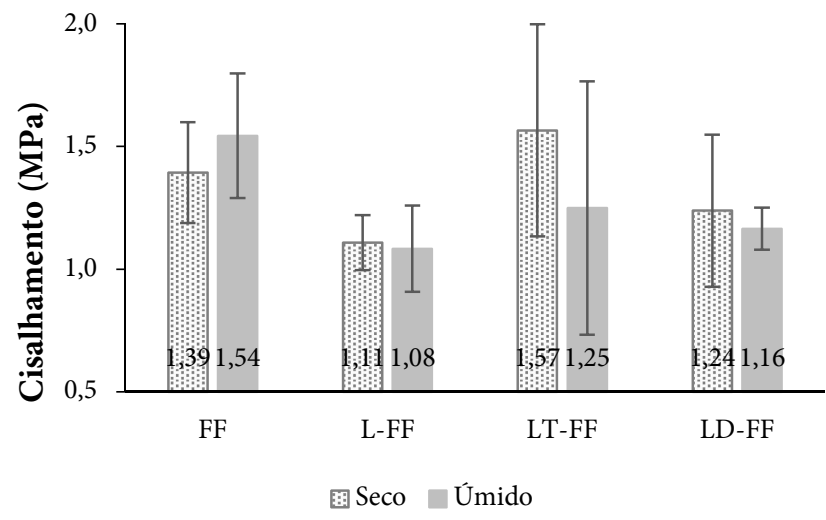

Figura 2. Média e desvio-padrão dos ensaios de cisalhamento da linha de cola dos painéis compensados. FF: fenolformaldeído; L-FF: lignina na condição in natura pósprecipitação; LT-FF: lignina tratada termicamente; LD-FF: lignina tratada com dicromato de potássio.

Figure 2. Mean and standard deviation of the shear strength of the resins of the plywood. FF: phenol formaldehyde; L-FF: post-precipitation lignin; LT-FF: thermally modified lignin; LD-FF: lignin modified with potassium dichromate.

A resina para a qual se observou menor resistência ao cisalhamento foi a L-FF, o que provavelmente pode ser justificada pela sua baixa viscosidade e baixo teor de sólidos. A baixa viscosidade da resina pode ter gerado uma fraca ligação entre as lâminas da madeira, comprometendo a qualidade da adesão (IWAKIRI, 2005).

Com relação aos resultados encontrados na literatura, os valores médios de resistência ao cisalhamento obtidos neste trabalho são similares aos observados por Iwakiri et al. (2002) para painéis compensados de Pinus taeda produzidos com resina FF. Os autores observaram valores entre 0,94 a 1,26 MPa. Abdelwahab \& Nassar (2011) encontraram valores que variaram de 1,58 $\mathrm{MPa}$ a 4,53 $\mathrm{MPa}$, sendo o primeiro referente às resinas $\mathrm{FF}$ com $0 \%$ de substituição de lignina e o segundo, resinas com substituição de $70 \%$.

Conforme pode ser observado na Figura 3, não houve diferença significativa para os tratamentos, após imersão em água por 24 horas. Akhtar et al. (2011) obtiveram resultados semelhantes de resistência em juntas coladas, ao estudar resinas de fenol-formaldeído lignosulfonatos.

As propriedades mecânicas de módulo de ruptura (MOR) e módulo de elasticidade (MOE) em flexão estática não foram afetadas pela adição de lignina na sua formulação $(\mathrm{F}>0,05)$ (Figura 3).

Os valores de MOR perpendicular foram de 3 a 4 vezes menor que os valores observados na direção paralela. Já os valores médios de MOE na direção perpendicular foram 6 a 9 vezes menores do que o MOE paralelo.

Segundo Tsoumis (1991), um compensado contendo um maior número de camadas resulta em maior uniformidade de resistência e rigidez, ao longo do comprimento (direção paralela) e largura (direção perpendicular), uma vez que durante o ensaio de flexão ocorre uma melhor distribuição das tensões que se desenvolvem durante o carregamento. Neste trabalho, os compensados foram produzidos utilizando apenas três lâminas de madeira, o que possivelmente resultou nesta diferença nos sentidos paralelo e perpendicular. 

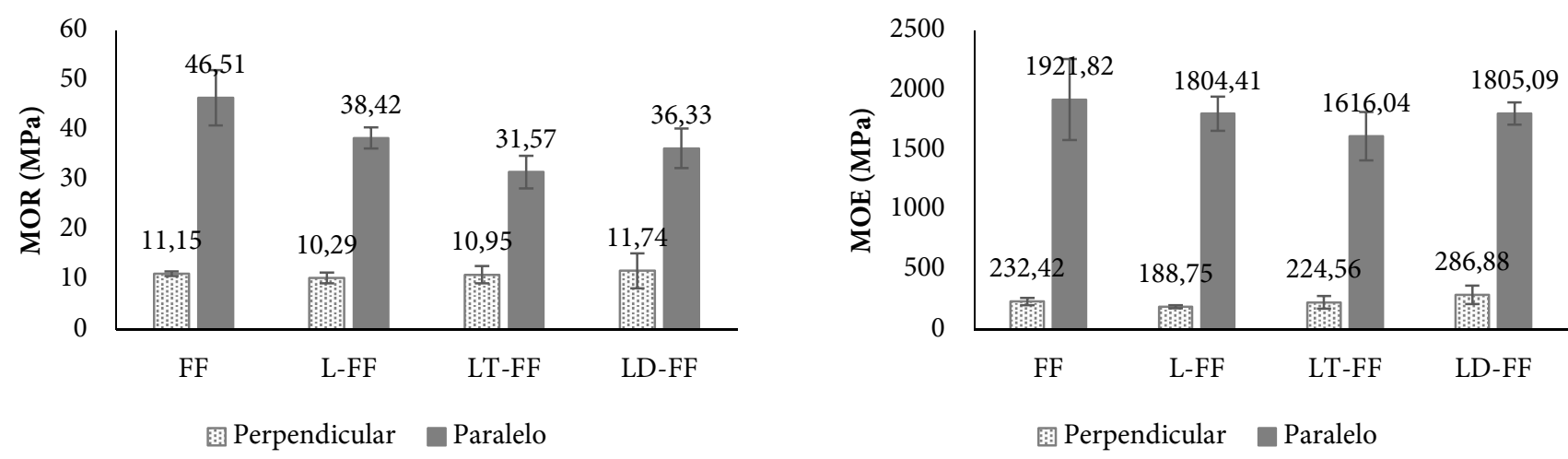

Figura 3. Módulos de ruptura (MOR) e elasticidade (MOE) em flexão estática. FF: fenol-formaldeído; L-FF: lignina na condição in natura pós-precipitação; LT-FF: lignina tratada termicamente; LD-FF: lignina tratada com dicromato de potássio.

Figure 3. Mean and standard deviation of the modulus of rupture (MOR) and modulus of elasticity (MOE) in static bending. FF: phenol formaldehyde; L-FF: post-precipitation lignin; LT-FF: thermally modified lignin; LD-FF: lignin modified with potassium dichromate.

\section{Conclusões}

É possível a utilização de lignina Kraft como substituta parcial (50\%) do fenol em adesivos fenol-formaldeído, uma vez que a adição de lignina Kraft no adesivo fenólico não afeta as propriedades do painel, o que favorece as suas condições de aplicabilidade.

Recomenda-se a utilização da resina a fenol-formaldeído com adição de lignina Kraft (L-FF) na produção de painéis compensados, devido principalmente, a manutenção das propriedades físicas e mecânicas quando comparado com aqueles produzidos a partir de lignina tratada termicamente (LT-FF) e tratada com dicromato de potássio (LD-FF).

\section{Referências}

ABDELWAHAB, N. A.; NASSAR, M. A. Preparation, optimisation and characterisation of lignina phenol formaldehyde resin as wood adhesive. Pigment \& Resin Technology, v. 40, n. 3, p. 169-174, 2011.

ABNT - ASSOCIAÇÃO BRASILEIRA DE NORMAS TÉCNICAS. NBR 12466-1: Madeira Compensada Qualidade de colagem. Parte 1: Métodos de ensaio. Rio de Janeiro, 2006.
AKHTAR, T.; LUTFULLAH, G.; ZAHOORUÇÇA, H. Lignosulfonate-phenolformaldehyde adhesive: a potenstial binder foro wood panel industries. Journal of the Chemical Society of Pakistan, v. 33, n. 4, p. 535-538, 2011.

ALMEIDA, R. R.; BORTOLETTO, G. J.; JANKOWSKY, I. P. Produção de compensados a partir da madeira de clones do híbrido Eucalyptus grandis $\times$ Eucalyptus urophylla. Scientia Florestalis, n. 65, p. 49-58, 2004.

ASMADI, M.; KAWAMOTO, H.; SAKA, S. Characteristics of softwood and hardwood pyrolysis in an ampoule reactor. Journal of Analytical and Applied Pyrolysis, v. 124, p. 523$535,2017$.

ASTM - AMERICAN STANDARD OF TESTING METHODS. D1084-97: Standard Test Methods for Viscosity of Adhesives. West Conshohocken, PA, 1997.

DAMÁSIO, R. A. P.; CARVAlHO, A. G.; GOMES, F. J. B.; CARNEIRO, A. C. O.; COLODETTE, J. L. Interação de nanocristais de celulose com o adesivo ureia-formaldeído em juntas coladas de Eucalyptus sp. Scientia Forestalis, v. 45, n. 113, p. 169-176, 2017.

FERDOSIAN, F.; PAN, Z.; GAO, G.; ZHAO, B. Bio-Based Adhesives and Evaluation for Wood Composites Application. Polymers, v. 9, n. 2, p. 1-29, 2017.

FIGUEIREDO, P.; LINTINEN, K.; HIRVONEN, J. T.; KOSTIANEN, M. A.; SANTOS, H. A. Properties and chemical modifications of lignin: Towards lignin-based nanomaterials for biomedical applications. Progress in Materials Science, v. 93, p. 233-269, 2018. 
GELLERSTEDT, G. Softwood Kraft lignin: Raw material for the future. Industrial Crops and Products, v. 77, p. 845-854, 2015.

HU, J.; ZHANG, Q.; LEE, D. Kraft lignin biorefinery: A perspective. Bioresource Technology, v. 247, p. 1181-1183, 2018.

IBRAHIM, V.; MAMO, G.; GUSTAFSSON, P.; HAITTIKAUL, R. Production and properties of adhesives formulated from laccase modified Kraft lignin. Industrial Crops and Products, v. 45, p. 343-348, 2013.

IWAKIRI, S. Painéis de madeira reconstituída. Curitiba: FUPEF, 2005. 247 p.

IWAKIRI, S.; DEL MENEZZI, C. H. S.; LAROCA, C.; VENSON, I.; MATOSKI, S. S. Produção de compensados de Pinus taedae e Pinus oocarpa com resina fenol-formaldeído. Cerne, v. 11, n. 2, p. 92-97, 2002.

IWAKIRI, S.; SILVA, L. S.; TRIANOSKI, R.; BONDUELLE, G. M.; ROCHA, V. Y. Avaliação do potencial de utilização da madeira de Schizolobium amazonicum "Paricá" e Cecropia hololeuca "Embaúba" para produção de painéis cimentomadeira. Cerne, v. 18, n. 2, p.303-308, 2012.

KALAMI, S.; AREFMANESH, M.; MASTER, E.; NEJAD, M. Replacing $100 \%$ of phenol in phenolic adhesive formulations with lignin. Journal of Applied Polymer Science, v. 134, n. 30, p. 1-9, 2017.

KALAMI, S.; CHEN, N.; BORAZJANI, H.; NEJAD, M. Comparative analysis of different lignins as phenol replacement in phenolic adhesive formulations. Industrial Crops and Products, v. 125, n. 1, p. 520-528.

KHAN, M. A; ASHRAF, S. M.; MALHOTRA, V. P. Development and characterization of a wood adhesive using bagasse lignin. International Journal of Adhesion and Adhesives, v. 24, n. 6, p. 485-493, 2004.

KOLLMANN, F. F. P.; KUENZI, E. W.; STAMM, A. J. Principles of wood science and technology: Wood based materials. V. II. New York: Berlin-Heidelberg, 1975. 703p.

OLIVARES, M.; GUZMÁN, J. A.; NATHO, A.; SAAVEDRA, A. Kraft lignin utilization in adhesives. Wood science and technology, v. 22, n. 2, p. 157-165, 1988.

PANG, B.; YANG, S.; FANG, W.; YUAN, T.; ARGYROPOULOS, D. S.; SUN, R. Structure-property relationships for technical lignins for the production of lignin-phenol-formaldehyde resins. Industrial Crops and Products, v. 108, p. 316-326, 2017.

TSOUMIS, G. Science and technology of wood: structure, properties, utilization. New York: Chapman \& Hall, 1991. 494p.

WANG, H.; PU, Y.; RAGAUSKAS, A.; YANG, B. From lignin to valuable products-strategies, challenges, and prospects. Bioresource Technology, v. 271, p. 449-461, 2019.

YANG, S.; WEN, J.; YUAN, T., SUN, R. Characterization and phenolation of biorefinery technical lignins for ligninphenol-formaldehyde resin adhesive synthesis. RSC Advances, v. 4, n. 101, p. 57996-58004, 2014.

ZHAO, J.; XIUWEN, W.; HU, J.; LIU, Q.; SHEN, D.; XIAO, R. Thermal degradation of softwood lignin and hardwood lignin by TG-FTIR and Py-GC/MS. Polymer Degradation and Stability, v. 108, p. 133-138, 2014.

ZHAO, X.; ZHANG, Y.; HU, H.; HUANG, Z.; YANG, M.; CHEN, D.; HUANG, K.; HUANG, A.; QIN, X.; FENG, Z. Effect of mechanical activation on structure changes and reactivity in further chemical modification of lignin. International Journal of Biological Macromolecules, v. 91, p. 1081-1089, 2016. 